\title{
The Relationship between the Emotional Intelligence and Reading Comprehension of Iranian EFL Impulsive vs. Reflective Students
}

\author{
Amir Reza Nemat Tabrizi ${ }^{1}$ \& Leila Esmaeili ${ }^{2}$ \\ ${ }^{1}$ Department of English Language, Payame Nour University, Iran \\ Correspondence: Amir Reza Nemat Tabrizi, Department of English Language, Payame Nour University, Iran. \\ E-mail: arnemati@pnu.ac.ir
}

Received: September 2, 2016

Accepted: October 30, 2016 Online Published: November 23, 2016

doi:10.5539/ijel.v6n6p221

URL: http://dx.doi.org/10.5539/ijel.v6n6p221

\begin{abstract}
The present article aimed at investigating the relationship between the emotional intelligence and reading comprehension of Iranian EFL impulsive and reflective students. To do so, 121 students based on a PET test were selected. Then, they answered a translated version of emotional intelligence and did a reading comprehension test. Later, they filled out impulsiveness questionnaire reflectiveness questionnaire. The results of these questionnaires and the reading test were compared. The first finding of the research revealed that there was a significant relationship between Iranian EFL learners' emotional intelligence and their reading comprehension. Based on the next result, it was concluded that there was significant relationship between impulsive Iranian EFL learners' emotional intelligence and their reading comprehension. On the other hand, there wasn't such relationship between reflective Iranian EFL learners' emotional intelligence and their reading comprehension. The last finding indicated that the Iranian impulsive EFL female students who possessed more degrees of emotional intelligence outperformed reflective students on reading comprehension. The findings of the research could be employed by EFL teachers, educational researchers, and English learners in an attempt to develop a more learner-centered method of second language reading comprehension.
\end{abstract}

Keywords: reading comprehension, EFL, impulsive, reflective learners

\section{Introduction}

\subsection{Introducing the Problem}

One of the skills that is of utmost significance in the instructional settings is the reading skill. In broad terms, reading is, "extracting the required information from (text) as efficiently as possible" (Grellet, 1988, p. 3). The importance of this skill lies in the fact that it is a means which provides readers with the significant deal of comprehensible input essential for both written and oral communication (Chastain, 1988). Farhady (1998) contends that since the discoveries in the realm of science and innovation are frequently presented in English language worldwide, reading in this language has gained supremacy among other languages skills and consequently, this skill occupies most of the time in second language classes in different countries. Reading skill is specially critical in input-poor EFL settings such as Iran, where there is very little (if any) contact with the native speakers of English and as a result, books, websites, and so forth remain the most available source of information in English (Rahimi, Sadighi, \& HosseinyFard, 2011). Apart from that, according to Grabe (2010), reading comprehension is viewed as a highly complex skill which encompasses both lower level processing and higher level processing. As Segalowitz (2003) argued, lower level processing is automatic and it is "fast; it is unstoppable (ballistic); it is independent of the amount of information being processed; it involves no awareness of processing; and it involves "pop-out" of the target item from the display" (p. 383). However, as Grabe (2010) points out, higher level processing is related to the ability of the reader to make an interpretation of the text based on their background knowledge. "Given the relationships between learners' EI and cognitive functioning, it may be reasonable to hypothesize that learners with higher level of EI would be able to carry out higher level processing (and hence read) both more effectively and efficiently" (Abdolrezapour \& Tavakoli, 2012, p. 4).

\subsection{Importance of the Problem}

Mikolajcozae \& Luminet (2008) argued that the emotional intelligence of the students has something to do with their disparities in comprehension, processing, sorting out, and controlling information. EI is about the smart 
utilization of feelings and using the power within the emotions to make the best decisions in the most effective ways (Ciarrochi \& Mayer, 2007).

On the other hand, in second language classes, it has been observed that there are some pupils who read accurately but do not comprehend what they have read. This issue may be attributable to the students' lack of knowledge of their own learning style (Soltani, Hadidi, \& Seifoori, 2015). One of the well-known learning styles which appears to be linked to language learning process and overall performance in language skills is "Impulsivity- Reflectivity" or "conceptual tempo" (Kagan, 1966).

This issue may be attributable to the learners' lack of knowledge about different types of their cognitive styles particularly their reflectivity or impulsivity. On the other hand, language instructors must also be sensitive to these individual variations in their everyday teaching. As Dörnyie (2001) stated, there must be a match between language teachers' methods in teaching and the learners' individual differences in cognitive styles. At the same time, reflective or impulsive learners might possess different levels of emotional intelligence. Identifying this type of interconnection among these variables seems to be highly significant as far as the reading comprehension of the learners is concerned.

\subsection{Relevant Scholarship}

The two prominent psychologists Salovey \& Mayer at Yale University believed that individuals possess some other sort of intelligence which is radically different from the cognitive intelligence. According to Stein (2009), the term "Emotional Intelligence" (EI) was first proposed by Salovey \& Mayer (1990) and ended up in being well-known by Goleman's works about Emotional Intelligence in 1995. From that year on, a lot of consideration has been given to it and the concept of EI has flourished as a new field in its own right. It has been extensively used in numerous areas from classrooms to workplaces (Richburg \& Fletcher, 2002).

Emotional intelligence has received a lot of enthusiasm in psychological circles as well as educational settings (Zeidner, Richard, \& Matthews, 2002). Emotional intelligence has been described as the ability to screen one's own and others' emotions and feelings, to distinguish among them, and to utilize this data to guide one's reasoning and action (Salovey \& Mayer, 1990). It is hypothesized that emotional intelligence is a variable that is valuable in predicting one's performance at school and work (AzimiTabar, Gorjian, \& Pazhakh, 2012). Various researches have proposed that emotional intelligence is a predictor of one's success in many fields, including effective teaching (Ghanizadeh \& Moafian, 2010), student learning (Brackett \& Mayer, 2003), and academic achievement (Fallahzadeh, 2011).

Motallebzadeh (2009) conducted a research among 170 Iranian EFL learners using Bar-On's (2003) emotional intelligence test to find out the relationship between the emotional intelligence of Iranian EFL learners and their reading comprehension and structural ability. The participants in their research were studying in English-related majors at Islamic Azad University (Torbat-e-Heidarieh \& Quchanbranhes). He concluded that "except for social responsibility and empathy as interpersonal categories, there was a strong relationship between Emotional Intelligence and EFL learners' reading comprehension and structural ability" (p. 39).

AzimiTabar, Gorjian, \& Pazhakh (2012) measured up the impact of EI as a whole on male and female high school students' performance in production and recognition test item formats. The participants in their study were high school students and their ages ranged from 15 to 17 studying at public high schools in Dezful \& Khuzestan. They came up with the conclusion that the male and female students' performance on multiple-choice and cloze tests is related to EI. In this study, the researchers didn't pinpoint to the exact subscales of EI which might be correlated with the students' reading comprehension.

Vahdat \& Khavandgaran (2013) conducted a study to find the relationship between verbal/emotional intelligence of Iranian EFL learners and their reading comprehension ability. The results were indicative of the fact that there was a meaningful relationship between the subjects' verbal intelligence and their reading comprehension ability. Participants in this study were 30 male and 30 female undergraduate students who were attending TOEFL classes at the Iran language institute in Shiraz. The average age of these participants ranged from 22 to 31. Moreover, the results confirmed that linguistic intelligence is a relatively strong predictor of reading performance compared to emotional intelligence.

MajidiDehkordi \& ShiraniBidabadi (2015) embarked on finding the relationship between Iranian EFL learners' reading strategy use and emotional intelligence. The results revealed that the degree of the utilization of meta-cognitive and cognitive strategies by the high EI group was greater than that of the low EI group, while with respect to the test-taking strategies, this degree of usage was weaker in the former than in the latter.

Brown (2007) asserted that there is a general consensus among language instructors and researchers that learning 
styles have special influence on language learning and acquisition. Among these styles, the reflectivity-impulsivity dichotomy is related to the degree to which a person ponders on the persuasiveness of a solution in solving problems that do not have clear-cut responses (Lesiak, 1978). Reflective individuals have the predisposition to analyze the possible solutions and select the most accurate one in order to avoid errors while impulsive people choose the first solution without thinking about its appropriateness (Michalska \& Zając-Lamparska (2015). Reiff (1992) stated that teachers have the capability to distinguish extremely impulsive or reflective students easily.

Reflectivity and impulsivity are both two features of individuals which have been identified to have close relationship with language learning process (Kagan, 1966). Michalska \& Zając-Lamparska (2015) believed that reflection-impulsivity dimension of cognitive style "manifests itself in situations in which a person is faced with a specific cognitive problem and must choose one of the possible solutions that compete with each other" (p. 574).

Kagan (1965) conducted a research among the first and second grade children and came up with the conclusion that there is a positive relationship between reading skill and reflectivity among these are students. He also observed that reflective children made fewer mistakes in reading in comparison with the impulsive ones. Doron (1973) was of the opinion that although reflective students are slower but they are also more accurate than impulsives in reading. In their research, Erickson \& Otto (1973) found that impulsive children appeared to perform weaker than reflective children on reading tasks. In their study, Hallahan, Kauffman, \& Ball (1973) concluded that the group of students who were low achievers contained 4 impulsive and one reflective person. The group of high achievers had four reflective and one impulsive student.

Hood \& Kendall (1975) investigated the kinds of reading errors committed by reflective and impulsive students. They came to the conclusion that with second grade learners, reflectives made fewer total errors than impulsives but the differences between them were not significant. Reflectives made significantly more graphically similar mistakes and made more corrections.

\subsection{Research Hypotheses}

In any research field, the approach adopted by the researcher to answer a research question or to test a hypothesis should be appropriate enough to yield the most plausible and reliable evidence. After surveying the area of language learning and teaching research, more specifically, language classroom research, and taking into consideration the aim of this research which is designed to assess the relationship between EFL learners emotional intelligence and their reading skill with respect their personality trait (reflective or impulsive) all in all, as it is clear, the design of this study is a descriptive one. Descriptive studies are conducted to demonstrate relationships between things in the world around you and also referred to as "correlational" or "observational" studies (Bickman \& Rog, 1998).

In order to fulfill the purpose of the study, the following research questions were proposed:

Q1: Is there any significant relationship between Iranian EFL learners' emotional intelligence and reading comprehension?

Q2: Is there any significant relationship between Iranian EFL impulsive learners' emotional intelligence and their reading comprehension?

Q3: Is there any significant relationship between Iranian EFL reflective learners' emotional intelligence and their reading comprehension?

Q4: In case of any relationship, is the significance of relationship the same for impulsive and reflective learners?

Based on the research questions set the following hypotheses were formulated:

H01: There is no significant relationship between Iranian EFL learners' emotional intelligence and reading comprehension.

H02: There is no significant relationship between Iranian EFL impulsive learners' emotional intelligence and their reading comprehension.

H03: There is no significant relationship between Iranian EFL reflective learners' emotional intelligence and their reading comprehension.

H04: The significance of this relationship is not the same for impulsive and reflective learners. 


\section{Method}

\subsection{Subsections of Method}

Through this section, it has been tried to describe the steps taken for carrying out the current study. More specifically, the section will provide information about the research design, participants, materials, instruments, and procedures that were employed in this study.

\subsection{Participants}

The participants of the study were 121 female EFL high school students studying at Emamat High School in Tabriz.

\subsection{Sampling Procedure}

The researchers selected one hundred and twenty one (121) students as homogeneous participants among 160 EFL learners after running a test of language proficiency (PET). The scores of these students were 1SD below and above the mean. Their age ranged between 16 and 19. Their mother tongues were Turkish.

\subsubsection{Sample Size}

The number of total samples in this study was $160 \mathrm{EFL}$ learners who were administered proficiency and based on the results 121 learner were selected.

\subsubsection{Measures and Covariates}

The following steps were pursued in conducting the present study: The PET (2005) test was used to homogenize learners according to their proficiency in English. Accordingly, 121 participants whose scores fell between one Standard Deviation above and below the mean were selected as a homogeneous group. After one week, they answered the emotional intelligence questionnaire prepared by Samuie et al. (2005) and they also answered the reading comprehension questions. The next session, they answered Barratt's impulsiveness questionnaire translated by Basharat \& HabibNejad (2009). In the same session, the students answered Kember et al.'s (2000) questionnaire translated by Kadivar et al. (2013). The results of the students' answers to the EQ questionnaire, the impulsiveness and reflectiveness questionnaires, and their scores in the reading comprehension test were compared in order to find out any possible relationship among the variables of the study.

To accomplish the purpose of the present study, the following research instruments were used:

\section{PET Test}

The first material that was utilized in this study is a standardized proficiency test, that is, Preliminary English Test (PET). This test contains two parts, reading and writing part, and listening and speaking parts. It was, however, not possible to check learners' speaking skill due to the impracticality of administering the full PET in the language institute and as a result, the researcher only utilized the reading and writing parts. The Reading part contains five sections which include 35 multiple choice questions, matching, true/false, and multiple choice cloze tests. The writing section contains 3 parts; part one includes five sentence transformation. Part two contains a short communicative message which is an email. The Listening part includes four sections.

\section{Bar-on's Questionnaire}

The second instrument was a translated, validated and revised version of Bar-On's (1980) emotional intelligence questionnaire prepared by Samuie et al. (2005) in Esfahan, Iran. This questionnaire originally contained 133 items in self-report format. Samuie et al. (2005) embarked on this project with the belief that in Iranian society we need access to an appropriate measurement tool that best fits our culture. They chose this questionnaire because of its comprehensiveness, simplicity, variety of questions and independence on foreign culture. After several modifications that they made up on this questionnaire, the final version turned out to have 90 items.

\section{Barratte's Questionnaire}

The third instrument was the Persian version of Barratt's impulsiveness questionnaire which is translated and validated by Basharat \& HabibNejad (2009). It has 30 items in self-report format on a 5-point scale (never, rarely, sometimes, often, and always). These items are scored to result in six first-order factors (attention, motor, self-control, cognitive complexity, perseverance, and cognitive instability impulsiveness) and three second-order factors (attentional, motor, and non-planning impulsiveness).

\section{Kember et al.'s Questionnaire}

The fourth instrument was the Persian version of Kember, Leung, Jones, \& Loke's (2000) reflective thinking scale. It was translated and validated by Kadivar, Tanha, \& Rahmani (2013). This questionnaire has 16 items on a 
5-point scale (Definitely agree to Definitely disagree) and it contains 4 scales: habitual action, understanding, reflection, critical reflection.

The fifth material utilized in this study was a reading comprehension test with 25 items. This test contained five passages with five questions in each passage. They were selected from the previous years' reading test items of Iranian national entrance exams of the state universities. These tests are designed every year by a panel of experts from Iran and they are validated and piloted before being given to the Iranian high school students throughout the country.

\section{Data Analysis}

\subsection{Recruitment}

As mentioned before, the PET (2005) test was used to homogenize learners according to their proficiency in English. In this test, we must have normal distribution of the scores. As can be seen in Table 1, the ratios of skewness and kurtosis over their respective standard errors were within the ranges of $+/-1.96$. As a result, the students' scores on the PET test enjoy normal distribution.

Table 1. Descriptive statistics; testing normality assumption in PET test

\begin{tabular}{llll}
\hline & & Statistic & Std. Error \\
\hline \multirow{4}{*}{ PET test } & Mean & 64.3313 & .61285 \\
& Std. Deviation & 7.75203 & \\
& Minimum & 40.00 & \\
& Maximum & 83.50 & \\
& Skewness & -.629 & .192 \\
& Kurtosis & 1.341 & .381 \\
\hline
\end{tabular}

Accordingly, 121 participants whose scores fell between one Standard Deviation above and below the mean were selected as a homogeneous group. The data obtained from the questionnaires and reading comprehension test were analyzed through Pearson correlation because the assumption of normality was met. As displayed in Table 2 , the ratios of skewness and kurtosis over their standard errors were lower than $+/-1.96$; hence normality of the data.

Table 2. Descriptive statistics; testing normality assumption

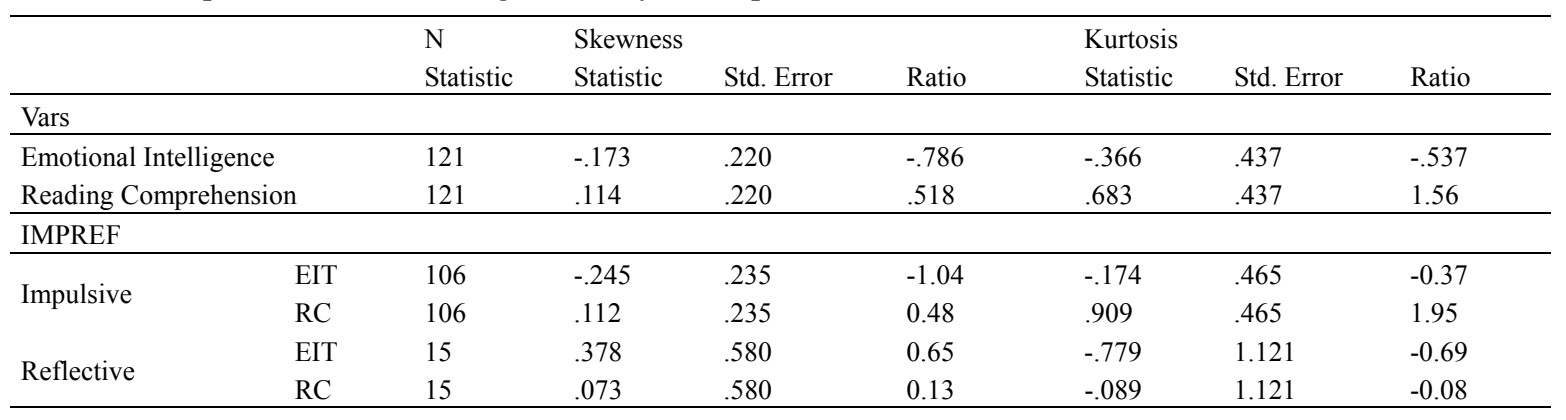

\subsection{Statistics and Data Analysis}

First Null-Hypothesis

There is no significant relationship between Iranian EFL learners' emotional intelligence and reading comprehension. The Pearson correlation was run to probe any significant relationships between Iranian EFL learners' emotional intelligence and reading comprehension in order to probe the first null-hypothesis. Based on the results displayed in Table $3,(\mathrm{r}(119)=.55, \mathrm{p}=.000$ representing a large effect size $)$ it can be claimed that there was a significant relationship between the two variables. Thus the first null-hypothesis was rejected. 
Table 3. Pearson correlation; emotional intelligence with reading comprehension

\begin{tabular}{lll} 
& & Reading Comprehension \\
\cline { 2 - 3 } Emotional & Pearson Correlation & $.550^{* *}$ \\
Intelligence & Sig. (2-tailed) & .000 \\
& $\mathrm{~N}$ & 121 \\
\hline
\end{tabular}

Note. ${ }^{* *}$. Correlation is significant at the 0.01 level (2-tailed).

\section{Second Null-Hypothesis}

There is no significant relationship between Iranian EFL impulsive learners' emotional intelligence and their reading comprehension. The results of the Pearson correlation ran $(\mathrm{r}(104)=.61, \mathrm{p}=.000$ representing a large effect size) to probe any significant relationships between Iranian EFL impulsive learners' emotional intelligence and reading comprehension indicated that there was a significant relationship between the two variables. Thus the second null-hypothesis was rejected.

Table 4. Pearson correlation; emotional intelligence with reading comprehension (impulsive group)

\begin{tabular}{lll}
\hline & & Reading Comprehension \\
\hline \multirow{2}{*}{ Emotional } & Pearson Correlation & $.947^{* *}$ \\
Intelligence & Sig. (2-tailed) & .000 \\
& $\mathrm{~N}$ & 121 \\
\hline
\end{tabular}

Note. $* *$. Correlation is significant at the 0.01 level (2-tailed).

\section{Third Null-Hypothesis}

There is no significant relationship between Iranian EFL reflective learners' emotional intelligence and their reading comprehension.

The Pearson correlation was run to probe any significant relationships between reflective Iranian EFL learners' emotional intelligence and reading comprehension. Based on the results displayed in Table 4, $(\mathrm{r}(13)=.29, \mathrm{p}$ $=.285$ representing an almost moderate effect size) it can be claimed that there was not any significant relationship between the two variables. Thus the third null-hypothesis was supported.

Table 5. Pearson correlation; emotional intelligence with reading comprehension (reflective group)

\begin{tabular}{lll}
\hline & & Reading Comprehension \\
\hline \multirow{2}{*}{ Emotional } & Pearson Correlation & .295 \\
Intelligence & Sig. (2-tailed) & .285 \\
& $\mathrm{~N}$ & 15 \\
\hline
\end{tabular}

\section{Fourth Null-Hypothesis}

The significance of this relationship is not the same for impulsive and reflective learners. The Fisher's z-transformation was computed to compare the two Pearson r-values between emotional intelligence and reading comprehension among impulsive and reflective groups. As it was displayed in Table 4 and Table 5; the impulsive subjects showed a higher relationship between reading comprehension and emotional intelligence than the reflective group ( $\left.\mathrm{r}_{\text {impulsive }}=.610 \mathrm{vs} . \mathrm{r}_{\text {reflective }}=.295\right)$. The results of Fisher's z-transformation $(\mathrm{z}=1.33, \mathrm{p}=.008)$ indicated that there was a significant difference between the two Pearson's r-values. Thus the fourth null-hypothesis was supported.

Table 6. Fisher's z-Transformation

\begin{tabular}{lllll}
\hline & Impulsive & Reflective & z-value & $\mathrm{P}$ \\
\hline Pearson Correlation & .610 & .295 & 1.33 & .008 \\
$\mathrm{~N}$ & 106 & 15 & & \\
\hline
\end{tabular}

\section{Discussion}

The first finding of the present study revealed that there was a significant relationship between Iranian EFL 
learners' emotional intelligence and reading comprehension. Regarding this finding, we can find the available literature very supportive (Motallebzadeh, 2009; AzimiTabar et al., 2012; Abdolrezapour \& Tavakoli's, 2012. However, this result is not in line with the findings of Rahimi et al. (2011), because their results were indicative of the fact that there was no significant difference among the students with various degrees of emotional intelligence and their reading ability.

Regarding the other results of the study, we found that there was a significant relationship between Iranian EFL impulsive learners' emotional intelligence and their reading comprehension but we couldn't find any tangible relationship between reflective Iranian EFL learners' emotional intelligence and reading comprehension. The last finding indicated that the significance of this relationship is stronger in impulsive students in comparison with reflective learners.

As mentioned earlier, as far as the researcher has browsed in the related literature on this regard, no work has been found to investigate the relationship between EFL learners' reflectivity/impulsivity and their emotional intelligence. Hence, these results are only partially in line with the findings of Kagan (1965); Doron (1973); Erickson \& Otto (1973); Hallahan et al. (1973); Hood \& Kendall (1975); Lesiak (1978); and Pirouznia (1994). On the other hand, the findings of the present study are not on a par with Ghapanchi \& Dashti (2011) who didn't find any significant relationship between the performance of reflective and impulsive students in reading comprehension questions.

The discrepancy between the findings of this research and those of the previous works might be attributable to the social context and behavioral factors of the learners taking part in the study.

Due to the pioneering focus of the present study which sought to probe the existence of any relationship between the EFL students' emotional intelligence, their impulsivity or reflectivity and their reading comprehension, it is too soon to come up with any generalizable conclusion to confirm or reject the existence of this kind of relationship without further comprehensive research with different gender and age groups of students from different parts of the world. As far as the findings of this research are taken into account, it can be claimed that the Iranian impulsive EFL female students who possess more degrees of emotional intelligence outperform emotionally intelligent reflective students on reading comprehension. EFL teachers, educational researchers, and English learners must be wary of interpreting the results of the present study in their everyday act of language learning and instruction.

The present study was also limited only to the EFL learners of the Tabriz High school students. This study might have some inherent limitations. It is only concerned with the reading ability of the subjects. The question of whether emotional inteligence had an effect on other language skills remained unanswered. Furthermore, the learner's age, social classes, cultural beliefs or religious attitudes, as well as the differences between circumstances of the various classes together with potential obstacles or advantages they may come across, were certainly ignored.

Additionally, investigation is limited to Iranian subjects with Azeri as their mother tongue and it is not clear whether the change of mother tongue would interfere with the research results. So, caution should be taken not to over generalize the results of this research beyond its scope.

\section{References}

Abdolrezapour, P., \& Tavakoli, M. (2012). The relationship between emotional intelligence and EFL learners' achievement in reading comprehension. Innovation in Language Learning and Teaching, 6(1), 1-13. http://dx.doi.org/10.1080/17501229.2010.550686

AzimiTabar, H., Gorjian, B., \& Pazhakh, A. (2012). The effect of emotional intelligence on male and female high school students' performance in production and recognition test item formats of reading comprehension. Advances in English linguistics, 1(3), 61-65.

Azizi, M. (1990). The impact of impulsivity/reflectivity on the EFL students'writing Ability (Unpublished master's thesis). University of Tehran, Tehran, Iran.

Basharat, M. A., \& HabibNejad, M. (2009). Personality tests. Tehran: Aiizh publication.

Brackett, M. A., \& Mayer, J. D. (2003). Convergent, discriminant, and incremental validity of competing measures of emotional intelligence. Personality and Social Psychology Bulletin, 29, 1147-1158. http://dx.doi.org/10.1177/0146167203254596

Brown, H. D. (2001). Teaching by principles: An interactive approach to language pedagogy. NY: Pearson Longman. 
Chastain, K. (1988). Developing second-language skills (3rd ed.). San Diego: Harcourt Brave Jovanocich.

Ciarrochi, J., \& Mayer, J. D. (2007). Applying emotional intelligence: A practitioner's guide. New York: Psychology Press.

Erickson, L., \& Otto, W. (1973). Effect of intra-list similarity and impulsivity-reflectivity on kindergarten children's word recognition performance. Journal of Educational Research, 66, 466-470. http://dx.doi.org/10.1080/00220671.1973.10884534

Fallahzadeh, H. (2011). The relationship between emotional intelligence and academic achievement in medical science students in Iran. Procedia-Social and Behavioral Sciences, 30, 1461-1466. http://dx.doi.org/10.1016/j.sbspro.2011.10.283

Farhady, H. (1998). Constructing reading comprehension tests. In H. Farhady (Ed.), Twenty-five years of living with applied linguistics: collection of articles (pp. 339-369). Tehran: Rahnama Press.

Ghabanchi, Z., \& Rastegar, R. (2014). The correlation of IQ and emotional intelligence with reading comprehension. The Reading Matrix, 14(2), 135-144.

Ghanizadeh, A., \& Moafian, F. (2010). The role of EFL teachers' emotional intelligence in their success. ELT Journal, 64(4), 424-435. http://dx.doi.org/10.1093/elt/ccp084

Ghapanchi, Z., \& Dashti, Z. (2011). The relationship between cognitive style of impulsivity and display, referential, and inferential reading comprehension questions among Iranian EFL university students. Canadian Social Science, 7(6), 227-233.

Grabe, W. (2010). Reading in a second language. In R. B. Kaplan (Ed.), Handbook of applied linguistics (2nd ed., pp. 88-99). New York: Oxford University Press. http://dx.doi.org/10.1093/oxfordhb/9780195384253.013.0006

Grellet, F. (1988). Developing Reading Skills. Cambrige: Cambridge University Press.

Hallahan, D., Kauffman, J., \& Ball, D. (1973). Selective attention and cognitive tempo of low achieving and high achieving sixth grade males. Perceptual and Motor Skills, 36, 579-583. http://dx.doi.org/10.2466/pms.1973.36.2.579

Hood, J., \& Kendall, J. A. (1975). Qualitative analysis of oral reading errors of reflective and impulsive second graders: a follow-up study. Journal of Reading Behavior, 7, 269-281. http://dx.doi.org/10.1080/10862967509547145

Kadivar, P., Tanha, Z., \& Rahmani, S. (2013). Reflective thinking; exploratory and confirmatory factor analysis. Scientific Information Database, 16(1), 50-64.

Kember, D., Leung, D., Jones, A., \& Loke, A. Y. (2000). Development of a questionnaire to measure the level of reflective thinking. Assessment and Evaluation in Higher Education, 25, 380-395. http://dx.doi.org/10.1080/713611442

Keshavarz, M. H., \& Cheraghi, A. (2005). On the relationship between impulsivity/reflectivity cognitive style and language proficiency test performance. Iranian Journal of Applied Linguistics, 8(1), 71-89. Retrieved from http://www.sid.ir/en/VEWSSID/J_pdf/87620050104.pdf

MajidiDehkordi, B., \& ShiraniBidabadi, F. (2015). Relationship between Iranian EFL learners' reading strategy use and emotional intelligence. International Journal of Foreign Language Teaching and Research, 3(9), $36-43$.

Mayer, J. D. (2005). What Is Emotional Intelligence (El)? Retrieved from http://www.unh.edu/emotional_intelligence/index.html.

Mikolajcozae, M., \& Luminet, O. (2008). Trait emotional intelligence and cognitive appraisal of stress full events: An exploratory study. Personality and Individual Differenced, 44, 1445-1453. http://dx.doi.org/10.1016/j.paid.2007.12.012

Motallebzadeh, K. (2009). The relationship between the emotional intelligence of Iranian EFL learners and their reading comprehension and structural ability. Journal of Teaching English as a Foreign Language and Literature, 1(4), 39-55.

Pirouznia, M. (1994). The impact of impulsivity/reflectivity on EFL reading comprehension (Unpublished master's thesis). University of Tehran, Tehran, Iran.

Pishghadam, R. (2011). Emotional Intelligence: Can it be a predicator of performance on different test formats? 
International Journal of Linguistics, $3(1), \quad 1-20 . \quad$ Retrieved from http://profdoc.um.ac.ir/articles/a/1022397.pdf

Rahimi, M., Sadighi, F., \& HosseinyFard, Z. (2011). Impact of linguistic and emotional intelligence on their reading performance of the Iranian EFL learners. The Journal of Teaching Language Skills, 3(1), 151-171. Retrieved from http://ecc.isc.gov.ir/ShwFArticle.aspx?aid=166790

Richburg, M., \& Fletcher, T. (2002). Emotional intelligence: Directing a child's emotional education. Journal of Child Study, 52(1), 31-38.

Segalowitz, N. (2003). Automaticity and second language learning. In C. Doughty \& M. Long (Eds.), The handbook of second language acquisition (pp. 382-408). Oxford: Blackwell. http://dx.doi.org/10.1002/9780470756492.ch13

Siegelman, E. (1969). Reflective and impulsive observing behavior. Child Development, 40(4), 1213-1222. http://dx.doi.org/10.2307/1127025

Soltani, K., Hadidi, N., \& Seifoori, Z. (2015). Iranian EFL learners' reflectivity/impulsivity styles and their metacognitive awareness of reading strategy use across gender. Journal of Instructional Evaluation, 8(31), 103-124. Retrieved from http://jinev.iaut.ac.ir/article_518883.html

Stein, S. J. (2009). Emotional Intelligence for Dummies. Mississauga: John Wiley \& Sons.

Zeidner, M., Richard, R., \& Matthews, G. (2002). Can emotional intelligence be schooled? A critical review. Educational Psychology, 37(4), 215-231. http://dx.doi.org/10.1207/S15326985EP3704_2

\section{Copyrights}

Copyright for this article is retained by the author(s), with first publication rights granted to the journal.

This is an open-access article distributed under the terms and conditions of the Creative Commons Attribution license (http://creativecommons.org/licenses/by/4.0/). 